\title{
Rethinking the Museum. Architecture's Lost Case
}

WOUTER DAVIDTS

For some time the museum world has been afflicted by what Stephen E. Weil once aptly described as a 'edifice complex' (Weil 1995a: 42). In recent decades, just about every museum has drastically renovated, expanded or added to the existing building, at least once. After all, building plans for museums create high expectations. Although architecture is stable, fixed by nature and thus motionless, museums seem to look upon it as the most appropriate medium to break new ground. Architecture is the medium par excellence to redefine and rearticulate their institutional position as well as their attitude. In the countless plans for additions and extensions, museum directors are seldom satisfied with making more space available, or just renovating the existing premises. On the contrary, with every museum building enterprise - whether an extension, an additional wing or a brand-new building - they explicitly express the ambition to tackle the 'institutional' space as well. Architecture is used as a vehicle to fundamentally rethink the museum on both a micro and a macro level - not only the commissioning institution itself, but the entire concept of 'the museum' as well. Architecture is capable - or so we are made to believe - of extending the museum's boundaries in both the literal and figurative senses. Thus, while preparing the recently finished renovation of the Museum of Modern Art in New York, Glen D. Lowry claimed that the project would entail more than an expansion of the existing facilities; the museum would "fundamentally alter its space." (Lowry 1998: 21) ${ }^{1}$ Whenever a mu-

1 This discourse is often enhanced by the rhetoric of the architects themselves. See for example Koolhaas (Koolhaas/O.M.A. 1997): "Throughout its history the Museum of Modern Art had used architecture as a vehicle of self-expression and 
seum starts to build, it pretends to do more than give itself a facelift, an implant, a correction, or an 'enlargement', to use beauty industry jargon. The phantasmagorical desire that the restyling of your body will guarantee a better and more rewarding life - epitomized by such television programmes as Extreme Makeover on ABC, I Want a Famous Face on MTV or Beautiful on VT4 - would seem to have infected museums and their directors too.

But what are the results of this general quest for fundamentally new spatial concepts for the museum? From the Neue Staatsgalerie, the Groninger Museum, Guggenheim Bilbao, Milwaukee Art Museum to Tate Modern, we have been regaled with the most diverse and spectacular architectural appearances, ranging from museums that look like hospitals, prisons, jewel boxes, spacecrafts, offices, and even all sorts of fishes. But has this architectural extravaganza offered a similar amount of thought-provoking institutional structures in exchange? In other words, did these buildings 'imply', bring about, even provoke totally different museum policies? Did all these exquisite bodies generate an equivalent amount of innovative and pioneering institutional personalities? Upon closer scrutiny of the kaleidoscopic collection of new museums and museum extensions of the last three decades, we must admit that, despite the euphoric, exhilarated tone of the discourse on museum architecture, very few genuinely innovative museum projects - with the same kind of combined architectural and institutional vigour as the Centre Pompidou, the eminent start of the so-called museum boom - have been completed. Few actual building projects, if none at all, have succeeded in setting the traditional museum typology - architectural as well as institutional - 'in motion', to paraphrase the title of one of the most important and remarkable publications on the museum discussion in the 1960s and 1970s: the seminal book Museum in ¿Motion? of 1979 , edited by Carel Blotkamp. ${ }^{2}$

regeneration, articulating and re-articulating its evolving understanding of modern art in built form [...]. At no other time since its foundings has the Museum had such a unique opportunity to undertake so extensive a redefinition of itself."

2 The most remarkable difference between the book and the symposium however was a peculiar feature of the title of the book. It may be regarded as a detail, but the question marks that the editors of the book Museum in Motion put in the title in 1979, were left in the designation of the 2003 conference. The editors of the book not only put a question mark at the end of the title, but also a reversed one before the word motion. Although this may be considered as a mere typographical joke, it represents the then 'disputable' state of the museum discussion. At that moment in time, there was still a lot of discussion, conflict and disagreement about the question if the museum of modern and contemporary art could be set in motion, and how this had to happen. I used the title Museum in ¿motion? again for a conference I organized in November 2004 in Sittard and Maastricht, The Netherlands. To consult the programme, visit: http://www. museuminmotion.tk 
Yoshio Taniguchi's rebuilding of the Museum of Modern Art in New York may be the largest and most expensive museum building enterprise of the last decades, it certainly does not convey a substantial breakthrough in our thinking about contemporary museum space, let alone the fundamental spatial alteration that was envisioned and promised - unless in terms of surface and scale, of course. The galleries for contemporary art are so large enough, to quote Hal Foster, "to contain King Kong in the next remake" (Foster 2004). The space may be spectacular - as an article by Rowan Moore in the New York Times Magazine suggested, picturing the trustees standing in a MoMA gallery in gala outfit - but nothing has really changed, unless the fact that the corporatization of MoMA has simply become more pervasive. It's remarkable that the entrance fee of MoMA is raised, after the recent extension, to the sum of $20,-\$$. Hal Foster rightly continues that "it is what you pay for some entertainments, and so places the museum more in the consumerist world than in the public sphere (however mythical): come for a big show, check out the new building, have lunch, hit the store - that's the ticket" (ibid.).

The rather thin crop of truly innovative museum projects is due to the paradoxical position architecture is forced to occupy within a museum commission on the one hand, and to the rather elliptical discourse on museum architecture on the other. Despite all the rhetoric, architecture has rarely been permitted to intervene in the actual spatial development of the museum programme. All too often, the ambition to use architecture to rethink the museum's programme and, by consequence, to develop a novel spatial framework to house that programme, is paradoxically shattered in the name of flexibility or programmatic freedom. Museums, with the museum of contemporary art as the absolute champion, simply do not allow architecture to get in the way of their ambitions. The museum of contemporary art wants to be at the absolute service of art and artists, so it is troubled by an almost paranoid desire for an architecture that is receptive, adaptable, and adjustable, or, in other words, flexible. But here we face the first paradox. Although architecture is compelled to apply the strategy of self-effacement, it must simultaneously address itself to helping the museum overcome its problems with art. Because after all - as it was defined as the core problem of the Museum in ¿Motion? Book of 1979 - art causes the museum a lot of trouble. Since the 1960s, art has drastically altered its nature and strategies: it has become ever more agile, critical toward the institutional framework of the museum, and eager to operate on more specific sites. The museum of contemporary art wants to keep up pace, but is confronted with spatial, institutional, and sociopolitical problems and limitations. It suffers from the unhappy conscience that it is never able to occupy a true place in the artistic present, as it always 'frames' art. This identity crisis incites the museum to indulge in ongoing self-critique, institutional introspection, and ultimately, self-denial. In recent 
decades, we have been confronted with dozens of museums that, following the artists, contest their own space and develop an anti-museum policy, some even going so far as to pretend to stop being a museum. The nature of this crisis however is fundamentally spatial. A quick glance at the metaphors used by museums to question their status, reveals the architectural bias of the crisis: if the museum of contemporary art wants to transform itself from a static repository for the art of the past into a dynamic workshop for the art of the present, it has to tear down its walls, open up its space, leave the premises, push back its frontiers, etc. Both the words 'repository' and 'workshop' imply a different spatial, and hence, architectural connotation. So it seems that architecture ended up in a quite ambiguous position: while it is obliged to refrain from intervention or mediation in the museum programme and is expected to produce so-called flexible and neutral spaces, it is nevertheless always put at stake within the critical questioning of that programme.

When Marcel Broodthaers was asked in an interview what space hided, he compared that pursuit to the children's game Lou es-tu là? or Wolf are you there? (Broodthaers 1974: 66). ${ }^{3}$ The relentless hunt for fundamental spatial alteration or the continuous drive to redefine the space of the museum amounts to nothing but a phoney game of hide-and-seek, to merely desperate attempts to deny the institutional conditioning of the museum interior. It does nothing but obscure the essence of art: its institutional encompassment and its resulting reification. The inexorable quest for new concepts of museum space is just a misleading game in which the players - artists, museum staff, but also architects - go to great pains to evade the true answer. Continuously, architecture is asked to meet the problematic desires of museums and other art institutions. They believe that architecture will enable museums to transform from a motionless stock into a vibrant workplace, from a place of passive spectatorship into a locus of active and animated cultural production, into an institution that is ultimately as un-institutional as possible.

This ambition was achieved, both fiercely and tragically, in the Centre Pompidou. The building tried to deliver a solution for the unpredictable development - and hence spatial and exhibitionary requirements - of the contemporary work of art, and express the image of a popular and iconoclastic art institution. And as Reyner Banham once remarked, it drove that question so far, that it elliptically handed it back (Banham 1977: 277-78). It's therefore not surprising that the Centre Pompidou was not only experienced as 'too flexible', but that its immense popularity also meant it was worn bare in nearly two decades. Although many international examples of purpose-built

3 'En effet, le loup dit chaque fois qu'il est ailleurs, et cependant il est là. Et l'on sait qu'il va se retourner et attraper quelqu'un. La recherche constante d'une définition de l'espace ne servirait qu'à cacher la structure essentielle de l'Art, un processus de réification.” (Broodthaers 1974: 66) 
museums of modern and contemporary art could be regarded as praiseworthy responses to the innovative manifesto of Piano \& Rogers, they could never rival its - albeit extremely problematic - radicality. None of the icons of the recent museum frenzy - such as the Neue Staatsgalerie in Stuttgart, the Getty Center in Los Angeles, The San Francisco Museum of Modern Art, the Guggenheim Bilbao, or Tate Modern - are truly innovative projects. On the contrary, most investment has been done, in one way or the other, in what Alma Wittlin could still categorize in 1970 as 'peripheral functions' (Wittlin 1970: 1). Whereas the core programme of the museum - the conservation, study and presentation of artefacts - used to take up about 90 per cent of the total surface of museums, this has shrunk to a mere 50 per cent. In the post-Pompidou era, about every museum has an elaborate gift shop, a fancy restaurant, a wellequipped concert hall or movie theatre, and in extreme cases, even a supermarket or shopping mall. The classic museum programme is seldom the key element of a building operation. Indeed, art museums are built for various reasons, few of them to do with art. What this means for architecture is that attention is now focused chiefly on the way it gives shape to this external programme. A museum design is no longer assessed primarily in terms of its intrinsic museological qualities, but on its response to the external programming package: whether it provides the city with a landmark, how it fits into the cityscape, whether it adds value to the surrounding urban fabric, stimulates city planning, distributes the museum's different peripheral functions in an interesting manner, and so on and so forth. All these kinds of design qualities have their importance, as they situate the role of museum buildings within a broader socio-economic, urban, and political context. Nevertheless, they demand evaluation criteria that, in a sense, are entirely detached from the assumed fundamental institutional change. They do not provide any new insight into the way in which the museum can function as a stage for contemporary art, and ultimately, the form that the museum - as an arsenal of memory could or ought to take. They may result in a building that - as the Guggenheim Bilbao - functions as the icon, sign, and logo of a city, all at once, but no longer cares about what's being shown inside, whether motorcycles, Armani costumes, or artworks. It's the building that takes care of the spectacle. When you visit the website of the Guggenheim Bilbao, the first heading you can click in is 'the building', the second is 'the exhibitions', and the third and last is 'the permanent collection'.

But does this mean that there's no critical space left for architecture in designing the core programme of the museum - developing a structure for the conservation, study and presentation of artefacts? Is there no vital role and significance to discern anymore for contemporary architecture within the construction of future museums? Has the fundamental rethinking of the museum turned out to be a lost case for architecture? Is the only thing architects are 
still allowed to do, to put their signature at the entrance, as Hans Hollein did already more than two decades ago in the Museum Abteiberg? Has architecture failed so dramatically that it is now being forced into a mere subserviant and benign position? A museum may still be one of the most prestigious commissions an architect can get, but is it as challenging as it used to be, or is said to be? Isn't it quite an exaggeration to declare that museums are "seismographs of architectural culture" (Lampugnani 1999: 13)? They may generate architectural discourse, but is it really the discourse that represents the most avant-garde practices in architectural theory and practice?

The traditional tasks of conserving, studying, and presenting artworks haven't lost their (public) relevance at all. Contemporary cultural production is no longer static and slowly evolving as in the 19th century, but almost totally commercialised, fleeting and mediatized. Within a society that is reigned by short-term agendas, instant memories, temporary regimes, provisional programmes, ephemeral networks, and impermanent flows, the traditional - some may call it old-fashioned, even conservative - programme of preservation and memory has become even more important than before. There, it may no longer be necessary to set the museum 'in motion' over and over again. Motion and speed are conditions and no longer qualities to strive for, quite the contrary. Museums can function as sites that provide the indispensable spatial and temporal enclave to study the inflationary field of culture from the sidelines and that install the necessary temporal margin to decide what in the end may be worth preserving, to decide which things we want to remember, after all. Contemporary culture runs the risk of disappearing in the visual sludge of our society. In the current era of the total blending of artistic disciplines, the dissolution of institutional domains, and the liquidation of critical distances, it seems all the more important to create temporal and spatial enclaves that allow for distinction, that afford room for difference.

\section{Museum Aan de Stroom - Xaveer De Geyter Architects ${ }^{4}$}

A museum design that radically subverted the standard logic of museum building commissions, was the design by Xaveer de Geyter Architects for the architecture competition Museum aan de Stroom (Museum by the River MAS). De Geyter refused to deliver what is expected from architecture in the design of a museum. First and foremost, he basically did what isn't expected. Having carefully scrutinized the brief, he detected a number of gaps in it,

4 For the following part, I largely depend on my article The Museum as Warehouse on the design of Xaveer De Geyter Architects for the Antwerp Museum Aan de Stroom (MAS) (see Davidts 2001). 
which he then transformed into the central issue of his design. It may come as no surprise then, that the project wasn't selected.

A key element of the MAS competition brief was that there were no precise or concrete programmatic specifications, but rather a specific institutional problem and an associated ambition on the client's part. The problem was that three Antwerp museums - the Museum of Folklore, the Vleeshuis and the Maritime Museum - were all short of space. The ambition was to turn the three into a single overarching historical museum - the Museum of Antwerp History. The future museum would be located on the Hanzestedenplaats, an ideal spot in the northern part of the city, on the edge of the Eilandje, between Willemdok and Bonapartedok. The Museum aan de Stroom - MAS was to be a museum building of international significance and so an architectural competition was announced. ${ }^{5}$

However, at the time the contest was announced, there was still no clearly thought-out and integrated vision of how the collections of the three independently operating museums were to be combined to create a single, allembracing historical museum. The competition rules said nothing about how the museum was to tell the story of the City of Antwerp. The only indication was provided by the floor area to be devoted to the permanent and the temporary exhibition spaces. Nothing was said, by contrast, about what form the City's memory was actually to take, and more specifically about how this 'permanent' presentation of the 'three collections/one history' might look, what its leading exhibits would be and whether it should be arranged chronologically or thematically.

De Geyter immediately recognized this manifest absence of a concrete institutional programme as an implicit invitation. The MAS AEFLTX project refused to act as if no issues were in play - an attitude displayed by other contenders, who began to think straightaway in terms of "the MAS building, ${ }^{6}$ It concentrated instead on the present institutional vacuum. By first imposing an institutional ambition on himself and only then looking at how to translate this architecturally, De Geyter did precisely what ought to have been done by the

5 Fifty-five teams submitted designs for the first, open stage of the competition. The jury selected five winners on 23 October 1999, according to the strength of their design and the expertise shown by the team. These were then asked to develop their designs. On 18 June 2000, the jury chose the design submitted by Neutelings/Riedijk Architecten as the overall winner.

6 AEFLTX was the code under which De Geyter's design took part in the second stage of the MAS competition. A striking feature of the designs submitted for the first stage of the MAS competition was that few, if any, of the participating teams submitted purely programmatic proposals. The vast majority of entries designed 'their' MAS building straightaway, with most of them opting for a highly defined form from the outset. For a review of the 55 initial submissions, see Davidts/De Meyer/Verschaffel (2000). 
museums themselves. Rather than creating a 'mature' body for an 'immature' memory, the project sought to conceive a scenario in which architecture and programme could take shape together.

The MAS project of De Geyter can be read as if it has been designed from the inside out. The initial design decisions are not dictated by the obligatory external programme, but are clearly taken in terms of the museum's classic 'internal' programme. Taking as its basis the individuality of the three collections to be brought together and housed, the design process began with the traditional memory function of the museum itself. De Geyter's point of departure was the idea that unifying the collections of the Vleeshuis, the Museum of Folklore and the Maritime Museum would produce such a quantity and diversity of objects - in terms of scale, physicality and value - that the operation would require a new museum model and a new spatial structure to go with it. The resultant museum would be served not only by neutral, contemplative exhibition spaces, but above all by a spatial structure in which that diversity could also be displayed.

To this end, the museum was conceived as a 'solid block of information' in which this volume and diversity could be highlighted by literally bringing the three collections together in one place. ${ }^{7}$ The museum would not only function as a classic and perfectly managed showcase, but also as a 'warehouse' a 'house of wares' - in which we show not only those things that we wish to remember, but the act of 'remembering' itself. Making the museum a warehouse and the warehouse a museum, puts the memory function of the museum itself on display. This means that visitors do not just encounter the supposed cream of the museum's collection, but its 'shadow collection' too - all the other 'stuff' that museums accumulate through their urge to remember. In this way, MAS AEFLTX would function not only as the showroom of the City's memory, but above all as its literal arsenal.

The resultant architectural structure, which was organized - entirely in keeping with the museological concept - according to the parallel shelf units in a warehouse, is sufficiently strong as to make all subsequent design decisions appear guided and conditioned by the overarching museum concept. The strategy of beginning with the delivery of a museum concept and only then allowing that concept to develop into a 'building', enabled De Geyter to be deliberately atypical in many respects and to avoid the need for compromise. Consequently, the project neatly sidesteps many of the traditional expectations towards museum architecture and refuses - in De Geyter's words to provide the right answers to the wrong questions.

7 Making the museum the overall repository of the three collections solved an inherent logistical problem at a stroke. The competition rules only envisaged a temporary storage space in the MAS building itself, with the collection as a whole spread - because of its scale - across a variety of storehouses in the city. 
The first place in which the radical nature of the design can be read is in the building's internal organization. Above all, MAS AEFLTX does not offer any classic exhibition spaces for the presentation of the permanent collection. On the contrary, the permanent collection is located 'on the shelves', as if in a warehouse. This means that the different objects can be presented neatly alongside one another, stacked or arranged otherwise. Panels, curtains, barriers and so on can be used to achieve different degrees of visibility and accessibility. A presentation structure of this kind does not, of course, match the classic credo of spatial flexibility. It would be difficult to fit a classic historical exhibition into these shelf units. Consequently, the architectural flexibility offered by MAS AEFLTX is conditioned a priori by the programme imposed at the outset, which has translated itself into a concrete presentation structure. But within that structure, MAS AEFLTX offers immense freedom and a huge range of possibilities.

The museum-warehouse concept subsequently dictated the organization of the museum's many additional functions, public or private. De Geyter did not organize the museum spaces around the public space, in the classic manner, but used the rigid pattern of shelf units as a kind of overall frame or matrix upon which the 'external' programme can relate to the basic museum programme. It was decided in this respect that only the 'archive' functions should be pushed into the warehouse pattern - an approach achieved by leaving specific 'voids' in the shelf structure. The other functions, which do not require a direct link with the storeroom - the entrance hall, for instance, the conference hall, the temporary exhibition spaces and the technical areas - were resolutely placed beneath the storeroom. In so doing, the design makes it plain that its architectural ambition is concentrated in the organization of the storeroom and in the interweaving of the museum's different archival functions.

The radical way in which the museum-warehouse concept is worked out in the interior is also expressed in the exterior. The maximum footprint and low volume - both of which result directly from the concept - produce a radical architectural object: MAS AEFLTX continues to look like a 'warehouse', which prevents the external programme from stealing the show - it is located literally beneath the surface. Moreover, its unusually sober form relieves the building of any obligation to fall in line with the classic urbanist expectations towards a museum. The internal logic of the design enables the building to make extremely relevant statements regarding the urban qualities that are demanded of new museum buildings. MAS AEFLTX refuses to meet the requirement to act as a landmark, to emphasize the site's existing 'axes', or to create the necessary public space in front of and around the museum. However, the internal logic of the design enables the building to make some extremely relevant statements regarding each of these three points. 
MAS AEFLTX does not attempt to address the classic notion of a 'landmark' as a building that literally marks the urban landscape through its sheer scale, its shape or its decoration. The design testifies to the recognition that nowadays buildings can imprint themselves in the city's 'collective memory' in many different ways. The frequent presence of architecture in the different media - from the popular to the cultural and promotional - means that buildings do not necessarily have to be large and flashy, but that they need above all to lead a 'public' life in order to become part of our 'heritage'. The project also adopted the principle that the 'serving tray' character of the Hanzestedenplaats was sufficiently pronounced that virtually any structure or architectural gesture would inevitably come over as grandiose.

This led to the idea that any structural articulation of axes or other planning details supposedly present on the site could only result in entirely irrelevant gestures or even in pure theatre. The pivotal function within the overall urban plan, the strategic link between city and harbour and the placement of a new stop on the 'cultural axis' running through Antwerp are all aspects that do not necessarily require formal expression and which, if they were expressed in that way, would by no means guarantee the public success of the project. This applies just as clearly to the way in which the project breaks with the cliché regarding public space, which has stated, ever since the generally acknowledged success of the square in front of the Centre Pompidou in Paris, that every museum has to have a square or some kind of large public space. De Geyter's principle was that there was already sufficient public and open space around the Hanzestedenplaats, especially around the different docks. He concluded, moreover, that the scale of the docks and quaysides is so gigantic that a classic square simply would not work at this location.

De Geyter's design for the MAS draws its strength primarily from its obstinacy and its fundamental unwillingness to deliver what is expected of museums today. It does not attract attention by being primarily beautiful and showy, but for the way in which it uses a combination of a museological and an architectural concept to sidestep the various commonplace ideas that have accreted around museum architecture. In numerous ways, however, it tackles the problems involved in contemporary architecture's unconventional approaches to the museum's internal and external programmes. An attitude as radical as this inevitably produces a design that cannot deliver the proverbial 'value for money'. However, through the MAS AEFLTX project, De Geyter conveys an understanding that bringing together three memories in a single shell is more than a question of simply relocating to a new and attractive body. There is a significant danger that that new body will rapidly lose its attraction. An operation of this nature simultaneously demands a fundamentally new structure and behaviour. Consequently, the question of whether $M A S A E F L T X$ is 'flexible' or not is, in a sense, irrelevant. De Geyter's project 
supplies the new museum not only with a new building, but also with a new programme and hence a different 'use'.

But then again, and the fact that the project of De Geyter wasn't chosen, showed it once more: it's up to the museums to let architecture interfere. But that requires guts, and, as Stephen Weil once laconically remarked, "Courage is rarely an institutional quality" (Weil 1995). In terms of fundamentally rethinking the museum through its architecture, the MAS project by De Geyter is undeniably a missed opportunity.

\section{Literatur}

Banham, Reyner (1977): “The Pompidolium”. In: Architectural Review, No. 963, May 1977, pp. 277-278.

Blotkamp, Carel (ed.) (1979): Museum in ¿Motion?: the modern art museum at issue/Museum in ¿beweging?: het museum voor moderne kunst ter diskussie, 's-Gravenhage: Govt. Pub. Office.

Broodthaers, Marcel (1974): "Dix Mille Francs de Récompense. Une interview d'Irmeline Libeer". In: Yves Gevaert (ed.), Marcel Broodthaers. Catalogue - Catalogus, Bruxelles, Société des Expositions du Palais des beaux arts de Bruxelles.

Davidts, Wouter (2001): "The Museum as Warehouse". In: Geert Bekaert (ed.), Xaveer De Geyter Architects. 12 projects, Gent/Amsterdam: Ludion, pp. 36-39.

Davidts, Wouter/De Meyer, Ronny/Verschaffel, Bart (2000): Museum Aan de Stroom/MAS Antwerp architectuurwedstrijd 1ste fase [Oktober 1999], Antwerp, Stad Antwerpen; Ghent, Vakgroep Architectuur \& Stedenbouw, Universiteit Gent.

Foster, Hal (2004): “It's Modern But Is It Contemporary?”. In: London Review of Books 26, no. 24, 16 December 2004.

Koolhaas, Rem/O.M.A (1997): Charrette. M(oMA), Rotterdam/New York: Office for Metropolitan Architecture.

Lampugnani, Vittorio Magnago (1999): “The Architecture of Art: The Museums of the 1990s”. In: Lampugnani, Vittorio Magnago (ed.), Museums for a New Millennium, Munich: Prestel.

Lowry, Glenn D. (1998): "The New Museum of Modern Art Expansion: A Process of Discovery". In: John Elderfield (ed.), Imagining the future of the Museum of modern art, New York: Museum of modern art/Harry N. Abrams, Inc.

Weil, Stephen E. (1995a): "A brief meditation on museums and the metaphor of institutional growth”. In: Stephen E. Weil (ed.), A Cabinet of Curiosi- 
ties. Inquiries into Museums and their Prospects, Washington: Smithsonian Institution Press.

Weil, Stephen E. (ed.) (1995): A Cabinet of Curiosities. Inquiries into Museums and their Prospects, Washington: Smithsonian Institution Press.

Wittlin, Alma Stephanie (1970): Museums. In Search of a Usable Future, Cambridge/Mass.: MIT Press. 